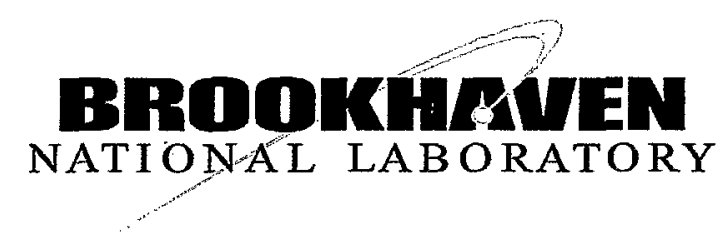

BNL- 75141 -2005-CP

\title{
FFAG Accelerator Proton Driver for Neutrino Factory
}

\author{
Alessandro G. Ruggiero \\ Presented at the NuFact 05 Workshop \\ Frascati, ROME \\ June $21-26,2005$
}

June 2005

\author{
Collider - Accelerator Department \\ Brookhaven National Laboratory \\ P.O. Box 5000 \\ Upton, NY 11973-5000 \\ www.bnl.gov
}

Notice: This manuscript has been authored by employees of Brookhaven Science Associates, LLC under Contract No. DE-AC02-98CH10886 with the U.S. Department of Energy. The publisher by accepting the manuscript for publication acknowledges that the United States Government retains a non-exclusive, paid-up, irrevocable, world-wide license to publish or reproduce the published form of this manuscript, or allow others to do so, for United States Government purposes. 


\section{DISCLAIMER}

This report was prepared as an account of work sponsored by an agency of the United States Government. Neither the United States Government nor any agency thereof, nor any of their employees, nor any of their contractors, subcontractors, or their employees, makes any warranty, express or implied, or assumes any legal liability or responsibility for the accuracy, completeness, or any third party's use or the results of such use of any information, apparatus, product, or process disclosed, or represents that its use would not infringe privately owned rights. Reference herein to any specific commercial product, process, or service by trade name, trademark, manufacturer, or otherwise, does not necessarily constitute or imply its endorsement, recommendation, or favoring by the United States Government or any agency thereof or its contractors or subcontractors. The views and opinions of authors expressed herein do not necessarily state or reflect those of the United States Government or any agency thereof. 


\title{
FFAG Accelerator Proton Driver for Neutrino Factory*
}

\author{
Alessandro G. Ruggiero, Brookhaven National Laboratory
}

\section{Introduction}

This paper is the summary of a conceptual study of a Proton Driver for Neutrino Factory based on the use of a Fixed-Field Alternating-Gradient (FFAG) Accelerator. The required proton energy range for an optimum neutrino production is 5 to $12 \mathrm{GeV}$. This can be accomplished with a group of three concentric rings each with $807 \mathrm{~m}$ circumference [1].

FFAG Accelerators [2] have the capability to accelerate charged particles over a large momentum range ( $\pm 30-50 \%)$ and the feature of constant bending and focusing fields. Particles can be accelerated very fast at the rate given by the accelerating field of $\mathrm{RF}$ cavities placed in proper locations between magnets. The performance of FFAG accelerators is to be placed between that of Super-Conducting Linear Accelerators (SCL), with which they share the fast acceleration rate, and Rapid-Cycling Synchrotrons (RCS), as they allow the beam to re-circulate over fewer revolutions.

Brookhaven National Laboratory is involved in the study of feasibility of FFAG Accelerators to accelerate intense beams of protons in the $\mathrm{GeV}$ energy range for a variety of applications the most important of which is the Upgrade of the Alternating Gradient Synchrotron (AGS) with a new FFAG injector [3] accelerating from $400 \mathrm{MeV}$ to $1.5 \mathrm{GeV}$. The ring would be housed in the AGS tunnel and has henceforth a circumference of $807 \mathrm{~m}$.

\section{Neutrino Factories}

A Neutrino Factory has the main goal to produce $10^{21}$ neutrino/a. This is done by having an intense beam of protons of energy between 5 and 12 $\mathrm{GeV}$ impinging on a radiation-resistant target, and by collecting $\mu$-mesons emerging from the reaction

$$
\mathrm{p}+\mathrm{X}>\pi^{ \pm}>\mu^{ \pm}>v
$$

and storing them in a storage ring where they decay in neutrinos in one long straight section directed toward the location of a massive detector placed at a very long distance.

Thus a main component of the Factory is the Proton Driver capable to deliver the required proton intensity at the proper energy. The proton accelerator could be a Super-Conducting Linac or a Rapid-Cycling Synchrotron. FFAG Accelerators can also be thought as Proton Drivers at high intensity and in the specified energy range as we shall show in this paper.

\footnotetext{
* Work performed under the auspices of the US DOE
}

The requirement is the delivery of protons with an average beam power of $4 \mathrm{MW}$ at the repetition rate of $25 \mathrm{~Hz}$ that gives $10^{14}$ protons per pulse at 10 $\mathrm{GeV}$ that is certainly within the capability of present accelerator technology. These figures are consistent with the presently perceived limitations of the target upon which the proton beam is to impinge.

\section{FFAG Accelerators for Proton Beams}

Two configurations and magnet arrangements have been proposed for an FFAG Accelerator [2]:

- Scaling Lattice that has the advantage of constant orbit parameters across the large momentum aperture but at cost of high bending fields, large magnet aperture and a limitation on available drift space.

- Non-Scaling Lattice where orbit parameters vary considerably across the momentum aperture but with the benefit of lower bending fields, smaller magnet aperture and allowance for more drift space. The engineering and construction of a FFAG Accelerator based on this principle are greatly simplified and expected to be more economical.

In case of proton beams, the concern of multiple resonance crossing is to be coupled to the presence of large space-charge forces at injection that, despite the fast rate by which the region of relevance is traversed, still may be significant. Moreover the longitudinal beam dynamics requires a careful analysis because of the fast frequency-varying $R F$ cavity system needed for acceleration. It is also possible to operate the accelerator in a Continuous Wave $(\mathrm{CW})$ mode of operation [4] with a continuous circulating beam.

The lattice of the FFAG Proton Driver we opt for is a Non-Scaling type made of a continuous sequence of FDF triplets. Each magnet has a combined bending and focusing function. The bending and the focusing alternate in sign between the three magnets of the triplet. The field profile in each magnet is purely linear. The beam is injected on an injection orbit placed toward the inside of the ring. The beam is accelerated and its trajectory spirals to the outside. Once the top energy is reached the beam is located on the far outmost orbit, the extraction trajectory, from which is extracted in a single turn. In the pulsed mode of operation there is only a single beam being accelerated that occupies only one trajectory. In this case multi-turn injection of negative ions is required to achieve the design intensity. Also, because the beam changes velocity continuously during acceleration, the RF cavity system is continuously tuned in frequency with the assistance of ferrite that limits the amount of voltage and acceleration rate. In the $\mathrm{CW}$ mode of operation, 
on the contrary, the beam is continuously accelerated and is present on every trajectory. In this case the beam is continuously injected turn-afterturn. The RF cavity system is tuned to a constant frequency and the beam is accelerated with a special voltage program designed to allow a programmable harmonic number jump from one turn to the next.

\section{FFAG Accelerators for Neutrino Factory}

We explored the possibility of using FFAG Accelerators for the acceleration of protons up to an energy of $12 \mathrm{GeV}$. This can be accomplished only with multiple rings that we assume to be concentric to each other and installed in the same tunnel, as shown in Figure 1. We assume that each ring can only accelerate over a momentum range of $\pm 40 \%$. There are then three of such rings. The first ring (Inj. Ring) accelerates protons from $400 \mathrm{MeV}$ to $1.5 \mathrm{GeV}$ and for its design we essentially copy that proposed for the AGS Upgrade program [3] with a circumference of $807 \mathrm{~m}$. The second ring ( $L E$ Ring) accelerates to $4.45 \mathrm{GeV}$, and the last one (HE Ring) to $11.6 \mathrm{GeV}$. They both have about the same circumference of the first ring. The transfer from one ring to the next occurs fast, in a single turn. The major parameters of the three rings are listed in. Table 1. We have assumed the same RF wavelength $(\lambda=5.9345 \mathrm{~m})$ for acceleration.

The three rings have the same periodicity and about the same circumference. They have thus also about the same lattice behavior, shown in Figure 2. The main magnet, drift and beam width parameters are listed in Table 2 . The beam width $\Delta x$ is the range that covers just the momentum excursion. To that one should add the contribution of betatron emittance at injection and extraction. The magnetic field strength required to cover the momentum range during acceleration is within the limit of roomtemperature magnet technology with the possible

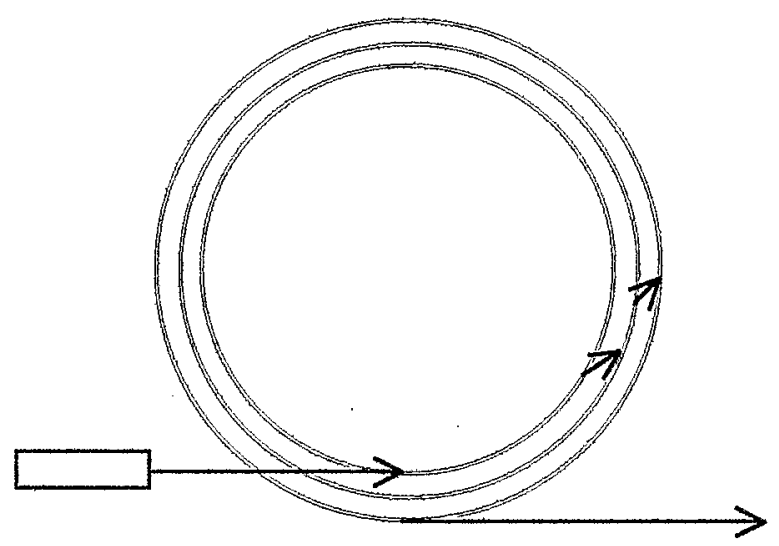

$\beta_{\text {保 }}$ in $m, \beta_{v}$ in $m, 10 x n$ in $m$ vs. dist. in $m$

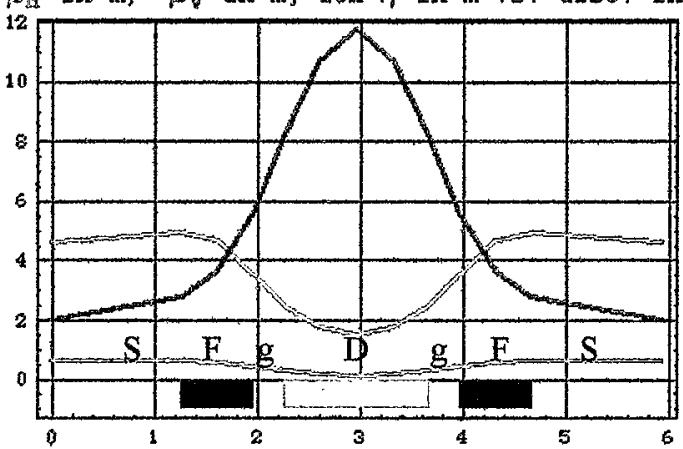

Figure 2. Lattice Functions along the Length of a Period

exception of the magnets in the HE ring where a field in excess of 2 Tesla is needed.

In the pulsed mode of operation injection of negative ions $(\mathrm{H})$ is required into the Injector Ring to reach the desired beam intensity. We take as a goal the acceleration of $10^{14}$ protons per pulse. The main injection parameters are listed in Table 3 . The beam size and intensity at the space-charge limit are given in Table 4.

Table 1. Major Parameters of the 3 FFAG Rings

\begin{tabular}{|c|c|c|c|c|}
\hline & & Inj. Ring & LE Ring & HE Ring \\
\hline $\begin{array}{r}\text { Energy: Inj. } \\
\text { Ext. }\end{array}$ & $\mathrm{GeV}$ & $\begin{array}{l}0.40 \\
1.50\end{array}$ & $\begin{array}{l}1.50 \\
4.45 \\
\end{array}$ & $\begin{array}{l}4.45 \\
11.6\end{array}$ \\
\hline $\begin{array}{l}\text { Inj. } \\
\text { Ext. }\end{array}$ & & $\begin{array}{l}0.7131 \\
0.9230\end{array}$ & $\begin{array}{l}0.9230 \\
0.9847 \\
\end{array}$ & $\begin{array}{l}0.9847 \\
0.9972 \\
\end{array}$ \\
\hline$\Delta \mathrm{p} / \mathrm{p}$ & $\pm \%$ & 40.45 & 40.43 & 40.41 \\
\hline Circumference & m & 07.091 & 818.960 & 830.829 \\
\hline No. of Periods & & 136 & 136 & 13 \\
\hline Period Length & $\mathrm{m}$ & 5.934 & 6.022 & 6.109 \\
\hline Harmonic No. & & 136 & 138 & 140 \\
\hline $\begin{array}{l}\text { Inj. } \\
\text { Ext. }\end{array}$ & $\mathrm{MHz}$ & $\begin{array}{l}36.02 \\
46.03\end{array}$ & $\begin{array}{l}46.03 \\
49.75\end{array}$ & $\begin{array}{l}49.75 \\
50.38 \\
\end{array}$ \\
\hline
\end{tabular}

\section{RF Acceleration}

At the end of the injection period, the beam is immediately accelerated by a RF cavity system that is ferrite tuned, at constant peak voltage. The frequency is chosen to be a sub-multiple of 201.25 $\mathrm{MHz}$ at injection. The RF is also matched from one ring to the next with about the same harmonic number It remains to be proven that the range of $R F$ chosen is suitable for the fast tuning of ferrite over a period of $6-10 \mathrm{msec}$ required for acceleration. Other concerns are the amount of voltage that a cavity gap can sustain and the capability of coping with beam loading with such large beam power. 
Table 2. Field Parameters

\begin{tabular}{|c|c|r|r|r|}
\hline & & Inj. Ring & LE Ring & HE Ring \\
\hline Drifts: $\mathrm{S}$ & $\mathrm{m}$ & 1.26725 & 1.28588 & 1.3045 \\
$\mathrm{~g}$ & $\mathrm{~m}$ & 0.30 & 0.3044 & 0.3088 \\
\hline F-sector: Length & $\mathrm{m}$ & 0.70 & 0.71029 & 0.72059 \\
Field min & $\mathrm{kG}$ & -0.78409 & -1.84918 & -4.23518 \\
Field max & $\mathrm{kG}$ & 3.79445 & 8.94876 & 20.4415 \\
Gradient & $\mathrm{Kg} / \mathrm{m}$ & 26.5817 & 60.8858 & 139.476 \\
\hline D-sector: Length & $\mathrm{m}$ & 1.40 & 1.42058 & 1.44118 \\
Field min & $\mathrm{kG}$ & 1.83450 & 4.32645 & 9.90888 \\
Field max & $\mathrm{kG}$ & -1.39962 & -3.30084 & -7.51787 \\
Gradient & $\mathrm{Kg} / \mathrm{m}$ & -23.2956 & -53.3590 & -122.236 \\
\hline$\Delta \mathrm{x}$ max, in F & $\mathrm{cm}$ & 17.22 & 17.46 & 17.69 \\
in D & $\mathrm{cm}$ & 13.88 & 14.07 & 14.26 \\
\hline
\end{tabular}

Table 3. Injection Parameters

\begin{tabular}{|l|c|r|}
\hline Injection Energy & $\mathrm{MeV}$ & 400 \\
\hline H Source Current & $\mathrm{mA}$ & 35 \\
\hline RFQ Transmission & $\%$ & 80 \\
\hline Chopping Ratio & $\%$ & 50 \\
\hline Inject. Beam Current & $\mathrm{mA}$ & 14 \\
\hline Inj. Protons / turn & & $3.3 \times 10^{11}$ \\
\hline Injected Turns & & 303 \\
\hline Pulse Length & $\mathrm{ms}$ & 1.144 \\
\hline Repetition Rate & $\mathrm{Hz}$ & 100 \\
\hline Duty Cycle & & 0.1144 \\
\hline
\end{tabular}

Table 4. Space-Charge, Beam Size and Beam Intensity

\begin{tabular}{|l|r|r|r|r|}
\hline & & Inj. Ring & LE Ring & HE Ring \\
\hline Protons / pulse & & $1.0 \times 10^{14}$ & $1.0 \times 10^{14}$ & $1.0 \times 10^{14}$ \\
\hline Ave. Beam Current & $\mathrm{mA}$ & 1.60 & 1.60 & 1.60 \\
\hline Ave. Beam Power & $\mathrm{MW}$ & 2.40 & 7.12 & 18.56 \\
\hline Full Nor. Emittance & $\pi \mu \mathrm{m}$ & 100 & 100 & 100 \\
\hline Act. Inj. Emittance & $\pi \mu \mathrm{m}$ & 98.32 & 41.69 & 17.68 \\
\hline Bunching Factor & & 4.0 & 4.0 & 4.0 \\
\hline Tune-Shift & & 0.343 & 0.188 & 0.085 \\
\hline Half Vert. Size & $\mathrm{cm}$ & 2.12 & 1.38 & 0.90 \\
\hline Half Hor. Size & $\mathrm{cm}$ & 3.41 & 2.22 & 1.46 \\
\hline
\end{tabular}

The possibility to operate a FFAG Accelerator in a $\mathrm{CW}$ mode of operation, for the delivery of a continuous beam on the target, is discussed in [4] and is based on the so-called principle of Harmonic Number Jump from one revolution to the next with a proper energy gain program and constant RF frequency. In this mode of operation the acceleration cycle is considerably shorter. We have assumed an $\mathrm{RF}$ of $201.25 \mathrm{MHz}$ for the Injector Ring, $805 \mathrm{MHz}$ for the LE Ring, and 3.2 GHz for the HE Ring, that require a lower amount of voltage per turn and that eventually can be made of superconducting cavities. All these frequencies are equal or multiple of the bunching frequency $(201.25 \mathrm{MHz})$ as the beam is delivered from the Injector Linac. The number of revolutions that the acceleration cycle takes in each of the three rings is respectively 175,151 and 115 .

Because we have adopted a Non-Scaling FFAG lattice with a Linear Field Profile there is a considerable large betatron tune shift during acceleration. Several integral tune values are crossed. The situation is the same for both Pulsed and CW Mode of operation, except to note that traversal of possible resonances is done considerably faster in the $\mathrm{CW}$ Mode of operation and that therefore is to be preferred.

\section{Conclusions}

Our feasibility studies show that FFAG Accelerators are suitable as Proton Drivers for beam power up to and exceeding $20 \mathrm{MW}$, beam energy up to $12 \mathrm{GeV}$, and repetition rate of $100 \mathrm{~Hz}$. There are nonetheless some issues that need to be addressed with a more careful study in the near future. They are: Large Space Charge Forces at Injection. To reach the high beam intensity multi-turn Injection of $\mathrm{H}^{-}$is needed. Both of these issues need a high energy Injector Linac. Magnets need to be designed properly showing capability to control misalignment and manufacturing imperfections. The fast acceleration rate in the pulsed mode of operation need a RF tunable system that can only be driven with ferrite. Finally with adoption of the NonScaling FFAG Lattice the beam will cross several resonances especially of first and second order. The beam stability in this case may be established only with careful computer simulations and tracking.

The capability to accelerate high-intensity proton beams of FFAG Accelerators is of the same level of that of SCL, and likely superior to that of RCS and Cyclotrons. But most important, because of the use of conventional room-temperature magnets, FFAG Accelerators could also be comparatively more economical.

\section{References}

[1] A.G. Ruggiero, BNL report C-A/AP/219, September 2005.

[2] J.S. Berg et al., Invited Talk to the $17^{\text {th }}$ Cyclotron Intern. Conf., Tokyo, Japan, October 2004.

[3] A.G. Ruggiero, Invited Talk to EPAC-04, July 2004, Lucerne, Switzerland.

[4] A.G. Ruggiero, BNL report C-A/AP/218, August 2005. 